\title{
Short-Term Effects of an Active Heat-and-Moisture Exchanger During Invasive Ventilation
}

\author{
Annia F Schreiber, Piero Ceriana, Nicolino Ambrosino, Manuela Piran, Alberto Malovini, and \\ Annalisa Carlucci
}

\begin{abstract}
BACKGROUND: Humidification is a standard of care during invasive mechanical ventilation. Two types of devices are used for this purpose: heated humidifiers and heat-and-moisture exchangers (HME). AIM: To compare the short-term physiologic effects of an active HME, with those of heated humidifiers and HMEs in terms of respiratory effort, ventilatory pattern, and arterial blood gases during invasive mechanical ventilation. METHODS: We conducted a randomized crossover study with 3 different devices in 15 stable subjects who had a tracheostomy and were ventilator-dependent. Transdiaphragmatic pressure, ventilatory pattern, arterial blood gases, and dyspnea scale were recorded at baseline and at the end of a 20 -min period with each device. RESULTS: Compared with heated humidifiers, the active HME was associated with higher diaphragmatic pressuretime product per minute (117.10 [interquartile range $\{$ IQR $\}$ 34.58-298.60]) versus 80.86 (IQR, 25.46-110.55) $\left.\mathrm{cm} \mathrm{H}_{2} \mathrm{O} \times \mathrm{s} / \mathrm{min}, P=.01\right)$, higher $\mathrm{P}_{\mathrm{aCO}_{2}}(48.50$ [IQR, 40.65-53.70] vs 39.60 [IQR, 37.50-49.95]) $\mathrm{mm} \mathrm{Hg}, P=.02)$ and lower $\mathrm{pH}(7.41$ [IQR, 7.36-7.49] vs 7.45 [IQR, 7.40-7.51], $P=.030)$ without any significant difference in ventilatory pattern. A significantly worse dyspnea scale score (active HME, 3 (2-4) vs heated humidifiers: 4 (3-5); $P=.009)$ was also observed. No significant differences were seen between active HME and HME. CONCLUSIONS: This study indicated that, compared with the heated humidifiers, the use of the active HME or the HME increased inspiratory effort, $\mathrm{P}_{\mathrm{aCO}}, \mathrm{pH}$, and dyspnea in stable subjects who were tracheostomized and ventilator-dependent. (ClinicalTrials.gov registration NCT02499796.) Key words: critical care; humidifiers; prolonged mechanical ventilation; tracheostomy; work of breathing; critically ill subjects. [Respir Care 2019;64(10):1215-1221. (C) 2019 Daedalus Enterprises]
\end{abstract}

\section{Introduction}

During invasive mechanical ventilation, the upper respiratory tract is bypassed by an endotracheal tube; as a

\footnotetext{
Drs Schreiber, Ceriana, Carlucci, and Ms Piran are affiliated with the Respiratory Intensive Care Unit, and Pulmonary Rehabilitation Unit, Istituti Clinici Scientifici Maugeri Istituto di Ricovero e Cura a Carattere Scientifico (IRCCS), Istituto Scientifico di Pavia, Pavia, Italy. Dr Schreiber is affiliated with the Division of Respirology, Department of Medicine, University Health Network, Toronto, Ontario, Canada. Dr Ambrosino is affiliated with the Istituti Clinici Scientifici Maugeri IRCCS, Istituto Scientifico di Montescano, Montescano Pavia, Italy. Dr Malovini is affiliated with the Laboratory of Informatics and Systems Engineering for Clinical Research, Istituti Clinici Scientifici Maugeri IRCCS, Istituto Scientifico di Pavia, Pavia, Italy.
}

Dr Schreiber presented some of the findings reported in this study at the European Respiratory Society International Congress, held September 2018, in Paris, France. consequence, artificial heating and humidifying inspiratory gases are needed. ${ }^{1}$ Two types of devices are used for this purpose: heated humidifiers and heat-and-moisture exchangers (HME). Heated humidifiers heat inspired gas in a water chamber, ${ }^{2}$ whereas HMEs retain heat and moisture during expiration and deliver them to the incoming gases during the next inspiration. ${ }^{3}$ Studies have assessed the effectiveness of these devices in preventing complications during invasive and noninvasive ventilation, ${ }^{4,5}$ whereas

\footnotetext{
The authors have disclosed no conflicts of interest.

Correspondence: Annia F Schreiber MD, Division of Respirology, Department of Medicine, University Health Network. 585 University Ave., Peter Munk Building, 11th Floor, Toronto, ON M5G 2N2, Canada. E-mail: annia.schreiber@icloud.com.
}

DOI: $10.4187 /$ respcare.06799 
other studies compared the short-term effects on respiratory effort and gas exchange. ${ }^{6-8}$ Compared with heated humidifiers, the use of HMEs in subjects who are intubated and on mechanical ventilation for acute respiratory failure, ${ }^{9,10}$ or during weaning trials from invasive ventilation, ${ }^{11}$ has been associated with higher work of breathing and decreased $\mathrm{CO}_{2}$ clearance despite an increase in minute ventilation. To our knowledge, no studies are available in stable subjects who are ventilator-dependent.

In the past decade, an active HME has been introduced to boost the humidifying performance of HMEs. It consists of a hybrid active device similar to an HME with a warming element fed by an electrical energy source that vaporizes water into the airways. This device has been shown to provide recommended ranges of absolute humidity levels in vitro; ${ }^{12}$ however, its effectiveness in clinical practice remains to be elucidated. Indeed, very few studies have been performed in the past decade to assess the effects of this device in vivo. Gonzalez et $\mathrm{al}^{13}$ found that the device was effective in delivering the appropriate amount of moisture to inspired gas in subjects who were tracheostomized and on mechanical ventilation, but its effects on respiratory effort or gas exchange were not assessed. Therefore, the aim of this study was to compare the short-term physiologic effects of the active HME with those of a heated humidifier and an HME during invasive ventilation in terms of respiratory effort, ventilatory pattern, and arterial blood gases in subject who were tracheostomized and ventilatordependent.

\section{Methods}

The experimental protocol was approved by the ethical committee of the Istituti Clinici Scientifici Maugeri (protocol $981 \mathrm{CE}$, May 5, 2014) and was registered at ClinicalTrials.gov. Written informed consent was obtained from each subject.

\section{Study Population}

Subjects who were tracheostomized and ages $>18$ y were enrolled from those admitted to the respiratory ICU of the Istituti Clinici Scientifici Maugeri, Istituto di Ricovero e Cura a Carattere Scientifico (IRCCS), Pavia, Italy, between May 2014 and December 2015 for weaning from prolonged mechanical ventilation, defined according to the National Association for Medical Direction of Respiratory Care Consensus Conference. ${ }^{14}$ Those subjects who, at the end of 4 weeks of hospitalization, were defined as ventilator-dependent and would have been discharged and requiring long-term home invasive ventilation were considered eligible for the study. At inclusion, subjects had to be clinically stable (ie, free of acute episodes, such as fever, pain, or hemodynamic instability, with

\section{QUICK LOOK}

\section{Current knowledge}

Humidification is a standard of care during invasive mechanical ventilation. Two types of devices are used for this purpose: heated humidifiers and heat-and-moisture exchangers. During both noninvasive and invasive mechanical ventilation for acute respiratory failure, heatand-moisture exchangers were associated with higher work of breathing and decreased carbon dioxide clearance when compared with heated humidifiers.

\section{What this paper contributes to our knowledge}

Results of our study indicated that, in subjects who were tracheostomized and ventilator-dependent, the use of an active heat-and-moisture exchanger similar to heatand-moisture exchangers, significantly increased patient inspiratory effort and worsened arterial blood gases and dyspnea compared with a heated humidifier, which, therefore, should remain the device of choice.

stable arterial blood gases defined as $\mathrm{pH}>7.35$ for at least a week). Exclusion criteria were the presence of acute respiratory failure $\left(\mathrm{pH} \leq 7.35\right.$, with $\mathrm{P}_{\mathrm{aCO}_{2}}$ $\geq 45 \mathrm{~mm} \mathrm{Hg}$ ), hemodynamic instability, encephalopathy, and lack of cooperation.

\section{Study Design}

The devices were compared by using a crossover design. All the subjects were ventilated with the same ventilator (Vivo 50, Breas Medical, Gothenburg, Sweden), with a single-limb circuit and an active non-rebreathing expiratory valve in pressure support ventilation mode with the setting prescribed by the clinician involved in the patient's care but not in the study. Standard tracheostomy tubes with inner diameters of 7 to $8.5 \mathrm{~mm}$ were used. The $\mathrm{F}_{\mathrm{IO}_{2}}$ was adjusted to obtain an $\mathrm{S}_{\mathrm{pO}_{2}}$ between $90 \%$ and $95 \%$ (delivered $\mathrm{O}_{2}, 0-5 \mathrm{~L} / \mathrm{min}$ ). The inspiratory positive airway pressure was set to obtain a tidal volume of $6-8 \mathrm{~mL} / \mathrm{kg}$, and an expiratory positive airway pressure of 3-7 $\mathrm{cm} \mathrm{H}_{2} \mathrm{O}$ was added according to the underlying pathology (Table 1). The inspiratory trigger was set at the most sensitive level that did not generate auto-triggering, and the expiratory trigger and rise time were adjusted according to each subject's clinical conditions and tolerance. The ventilatory settings remained unchanged throughout the study protocol.

As in previous physiologic studies, ${ }^{6,7,11}$ each awake subject was positioned in the semi-recumbent position and underwent 3 consecutive 20 -min periods of evaluation with- 


\section{Short-Term Physiologic Effects of Active HMEs}

Table 1. Demographic, Anthropometric, Clinical, and Physiologic Characteristics of Study Subjects and Ventilator Setting

\begin{tabular}{|c|c|c|c|c|c|c|c|c|c|c|c|}
\hline $\begin{array}{l}\text { Subject } \\
\text { no. }\end{array}$ & Diagnosis & Sex & Age, $y$ & $\begin{array}{l}\mathrm{BMI}, \\
\mathrm{kg} / \mathrm{m}^{2}\end{array}$ & $\mathrm{pH}$ & $\begin{array}{c}\mathrm{P}_{\mathrm{aO}_{2}} \\
\mathrm{~mm} \mathrm{Hg}\end{array}$ & $\begin{array}{l}\mathrm{P}_{\mathrm{aCO}_{2}}, \\
\mathrm{~mm} \mathrm{Hg}\end{array}$ & $\begin{array}{l}\text { Ventilator } \\
\text { mode }\end{array}$ & $\begin{array}{l}\mathrm{ID} \\
\mathrm{mm}\end{array}$ & $\begin{array}{l}\text { IPAP, } \\
\mathrm{cm} \mathrm{H} \mathrm{H}_{2} \mathrm{O}\end{array}$ & $\begin{array}{l}\text { EPAP, } \\
\mathrm{cm} \mathrm{H}_{2} \mathrm{O}\end{array}$ \\
\hline 1 & COPD & $\mathrm{F}$ & 73 & 23.6 & 7.45 & 76.2 & 41.9 & PSV & 7 & 18 & 4 \\
\hline 2 & COPD & M & 74 & 20.2 & 7.42 & 78.4 & 61.3 & PSV & 7 & 19 & 4 \\
\hline 3 & COPD & $\mathrm{M}$ & 74 & 31.0 & 7.48 & 85.0 & 47.0 & PSV & 7 & 20 & 6 \\
\hline 4 & COPD & M & 84 & 20.2 & 7.42 & 70.4 & 53.5 & PSV & 7.5 & 14 & 5 \\
\hline 5 & ALS & M & 71 & 22.7 & 7.56 & 76.0 & 22.1 & PSV & 8 & 23 & 4 \\
\hline 6 & COPD & $\mathrm{M}$ & 58 & 21.8 & 7.45 & 76.8 & 36.0 & PSV & 8 & 15 & 4 \\
\hline 7 & Postoperative & M & 68 & 20.3 & 7.46 & 62.1 & 31.6 & PCV & 7.5 & 13 & 4 \\
\hline 8 & Pachypleuritis & $\mathrm{M}$ & 70 & 24.2 & 7.48 & 128.0 & 48.5 & PSV & 7.5 & 16 & 3 \\
\hline 9 & COPD & $\mathrm{F}$ & 64 & 18.0 & 7.41 & 117.0 & 55.5 & PSV & 7 & 18 & 3 \\
\hline 10 & COPD & $\mathrm{F}$ & 75 & 25.3 & 7.36 & 64.9 & 55.6 & PSV & 7.5 & 20 & 6 \\
\hline 11 & Bronchiectasis & $\mathrm{F}$ & 73 & 23.9 & 7.44 & 65.8 & 46.2 & PSV & 7.5 & 18 & 3 \\
\hline 12 & Polyneuropathy & $\mathrm{M}$ & 83 & 27.7 & 7.52 & 76.5 & 33.9 & PSV & 8 & 14 & 4 \\
\hline 13 & $\begin{array}{l}\text { Guillain Barré } \\
\text { syndrome }\end{array}$ & M & 51 & 30.8 & 7.48 & 62.7 & 35.5 & PSV & 8.5 & 14 & 4 \\
\hline 14 & ALS & $\mathrm{M}$ & 58 & 27.6 & 7.55 & 77.6 & 26.4 & PCV & 8.5 & 14 & 4 \\
\hline \multirow[t]{3}{*}{15} & COPD & $\mathrm{F}$ & 81 & 28.1 & 7.49 & 72.9 & 43.6 & PSV & 8 & 26 & 7 \\
\hline & Median & NA & 73.07 & 23.9 & 7.46 & 76.2 & 43.6 & NA & 7.5 & 18 & 4 \\
\hline & $\mathrm{IQR}$ & NA & $66.2-74.7$ & $21.1-27.6$ & $7.43-7.48$ & $68.1-78.0$ & $34.7-51$ & NA & $7-7.5$ & $14-19.5$ & $4-4.5$ \\
\hline $\begin{array}{l}\text { BMI }=\text { bod } \\
\text { ID }=\text { inner } \\
\text { IPAP }=\text { ins } \\
\text { EPAP }=\text { ex } \\
\text { PSV }=\text { pre } \\
\text { ALS }=\text { am } \\
\text { PCV }=\text { pre } \\
\text { NA }=\text { not } \\
\text { IQR }=\text { inte }\end{array}$ & $\begin{array}{l}\text { mass index } \\
\text { iameter } \\
\text { ratory positive airway } \mathrm{p} \\
\text { ratory positive airway } \mathrm{p} \\
\text { ure support ventilation } \\
\text { trophic lateral sclerosis } \\
\text { ure-controlled ventilatio } \\
\text { plicable } \\
\text { uartile range }\end{array}$ & $\begin{array}{l}\text { ssure } \\
\text { ssure }\end{array}$ & & & & & & & & & \\
\hline
\end{tabular}

out intervals and with the 3 devices applied in random order. The investigators took care to ensure that the study variables remained constant in terms of duration, environment, position, and other possible conditions that could potentially affect the stability of the patient. The HME (Humid-Vent Compact, Teleflex Medical, Kamunting Perak, Malaysia) and the active HME (Medisize Hygrovent Gold, Healthcare Solutions, Lenexa, Kansas) were positioned between the mount catheter and the expiratory valve. The heated humidifier (MR810, Fisher \& Paykel Healthcare, Auckland, New Zealand) was placed between the ventilator and the expiratory valve. The main characteristics of the 3 devices are shown in Figure 1 and in Table 2.

\section{Measurements}

Data were recorded in the final $5 \mathrm{~min}$ of each ventilation period. The following variables were measured:

Flow was assessed by means of a heated pneumotachograph and a differential pressure transducer (Honeywell, Freeport, IL; $\pm 300 \mathrm{~cm} \mathrm{H}_{2} \mathrm{O}$ ) connected to the proximal tip of the expiratory valve. Tidal volume was assessed by integration of the flow including inspiratory $\left(\mathrm{T}_{\mathrm{I}}\right)$, expiratory $\left(\mathrm{T}_{\mathrm{E}}\right)$, and total respiratory time $\left(\mathrm{T}_{\text {tot }}\right)$. Breathing fre-

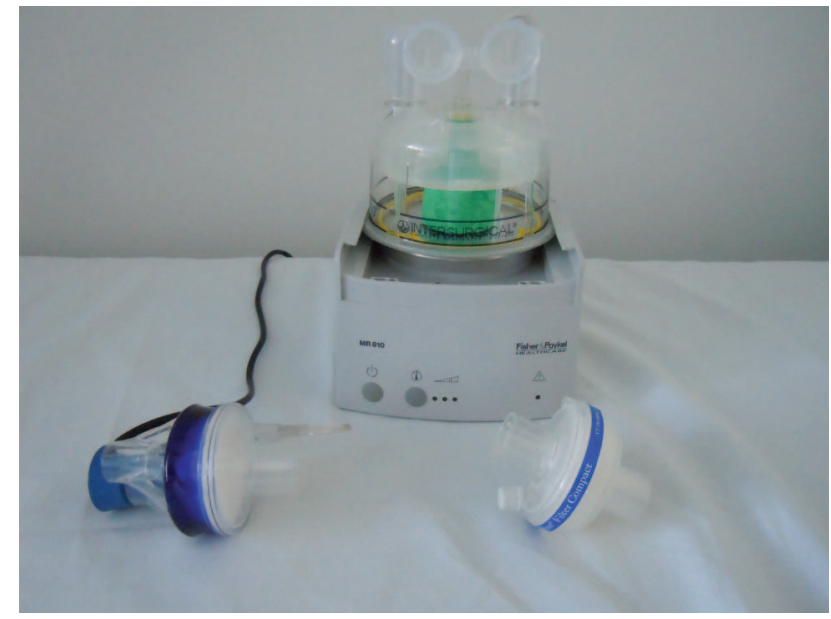

Fig. 1. From left to right: Active HME (Medisize Hygrovent Gold), Heated Humidifier (MR810) and Heat-and-moisture exchanger (HME) (Humid-Vent Compact).

quency and minute ventilation were computed from the flow signal.

Airway pressure was measured via a side port between the pneumotachograph and the expiratory valve. Esophageal pressure and gastric pressure were measured with a 
Table 2. Device Characteristics

\begin{tabular}{lccc}
\hline \hline Device Characteristic & HME & Active HME & Heated Humidifier \\
\hline Dimensions, mm & $60 \times 70$ & $60 \times 80$ & $94 \times 154 \times 135$ \\
Weight, g & 31 & 42 & 1,700 \\
Volume, $\mathrm{mL}$ & 35 & 59 & 500 \\
Resistance, $\mathrm{cm} \mathrm{H} \mathrm{H}_{2} \mathrm{O}$ & $1.8,60 \mathrm{~L} / \mathrm{min}$ & $\mathrm{NR}$ & $\mathrm{NR}$ \\
Dead space, $\mathrm{mL}$ & 35 & 59 & NA* \\
& & & \\
$*$ Because the heated humidifier is placed between the ventilator and the expiratory valve, its \\
volume does not contribute to any increase in the dead space. \\
$\mathrm{HME}=$ heat-and-moisture exchanger \\
$\mathrm{NR}=$ not reported \\
$\mathrm{NA}=$ not applicable
\end{tabular}

balloon catheter system. ${ }^{15}$ The proper position of the esophageal balloon was verified by means of the occlusion test. ${ }^{15}$ Transpulmonary and transdiaphragmatic pressure swings were obtained by subtracting esophageal pressure from airway pressure and gastric pressure, respectively.

The dynamic intrinsic PEEP was estimated according to Appendini et al. ${ }^{16}$ The magnitude of the inspiratory muscle effort was estimated from the pressure-time product of the diaphragm and from the esophageal pressure-time product of the inspiratory muscles. The pressure-time integrals were calculated per breath and per minute. ${ }^{17}$ Dynamic lung compliance and pulmonary resistances at mid-inspiratory volume were computed from transpulmonary pressure, flow, and tidal volume as previously described. ${ }^{16}$

$\mathrm{P}_{\mathrm{aO}}$ and $\mathrm{P}_{\mathrm{aCO}}$ were assessed under mechanical ventilation by means of a blood gas analyzer (ABL 520-Radiometer, Copenhagen, Denmark) at baseline and at the end of each trial. The level of dyspnea was recorded at the end of each trial by the means of an arbitrary subjective scale that ranged from 0 (worst) to 5 (no dyspnea). Heart rate, electrocardiogram, arterial blood pressure, and $\mathrm{S}_{\mathrm{pO}_{2}}$ were continuously monitored.

\section{Statistical Analysis}

Sample-size calculations were performed by using the G*Power v3.1.9 software tool. ${ }^{18,19}$ Sample-size calculations showed that data from 15 cases were required to reach statistical power $(1-\beta)=.80$ with a significance level $(\alpha)=.017$ (including Bonferroni correction for the following 3 comparisons: heated humidifier vs HME, heated humidifier vs active HME, and active HME vs HME) when detecting the differences in the analyzed parameters between devices that corresponded to a esophageal pressure-time product mean value of 156 of $156 \pm 63 \mathrm{~cm} \mathrm{H}_{2} \mathrm{O} \times \mathrm{s} / \mathrm{min}$ for HME and of $112 \pm$ $49 \mathrm{~cm} \mathrm{H}_{2} \mathrm{O} \times \mathrm{s} / \mathrm{min}$ for heated humidifier as observed by Lellouche et $\mathrm{al}^{6}$ in subjects who were noninvasively ventilated, with an expected correlation between measure- ments $=0.70$ (2-sided Wilcoxon signed-rank test). Randomization among the 3 systems was performed according to Altman and Bland.20

The distribution of quantitative variables was described by using the median (25th and 75th percentiles or interquartile range) and categorical variables by count and frequency (\%). Statistically significant differences in the distribution of quantitative variables among different humidifiers were assessed by the Friedman test; pairwise comparisons were performed by the Wilcoxon signed-rank test. The Bonferroni correction was applied to adjust for multiple testing based on the number of pairwise comparisons by variable when performing between-ventilator comparisons $(n=3)$; otherwise, $P<.05$ was considered statistically significant. Linear mixed-effects models and post hoc comparisons were also performed. Parallel coordinate plots were generated by custom R scripts. Statistical analyses were performed by the R statistical software tool v3.4.1 (www.r-project.org).

\section{Results}

Fifteen consecutive subjects were studied. Patient demographic, anthropometric, clinical and physiologic characteristics, and ventilator settings are shown in Table 1. The physiologic effects of the 3 devices are shown in Table 3. Compared with both active HME and HME, the pressure-time product of the diaphragm per breath was significantly lower with heated humidifier, without any significant difference between active HME and HME. The pressure-time product of the diaphragm per minute was significantly higher with active HME compared with heated humidifier but not with HME. Compared with heated humidifier, active HME showed a significant increase in $\mathrm{T}_{\mathrm{I}} / \mathrm{T}_{\text {tot }}$ and a nonsignificant increase in dynamic intrinsic PEEP. There were no significant differences in tidal volume, breathing frequency, and minute ventilation among the 3 systems.

$\mathrm{P}_{\mathrm{aCO}}$ was significantly higher and $\mathrm{pH}$ was significantly lower with active HME compared with heated humidifier; respiratory acidosis occurred in 3 of 15 cases. There was no significant difference in $\mathrm{P}_{\mathrm{aCO}}$ and $\mathrm{pH}$ between the active HME and the HME, and no significant difference in $\mathrm{P}_{\mathrm{aO}_{2}}$ among the 3 systems. Dyspnea was significantly lower with a heated humidifier compared with both the active HME and the HME. There were no significant differences between active HME and HME. In 4 of 15 subjects, the active HME period was halted due to unbearable dyspnea and severe desaturation, as shown by a prolonged $\mathrm{S}_{\mathrm{pO}_{2}}$ of $<80 \%$. The individual pressure-time products of the diaphragm per minute values during the 3 different trials are shown in Figure 2. 


\section{Short-Term Physiologic Effects of Active HMEs}

Table 3. Distribution of Ventilator Parameters and Arterial Blood Gases by Heated Humidifier, Active HME, and HME

\begin{tabular}{|c|c|c|c|c|c|c|c|}
\hline \multirow[b]{2}{*}{ Variable } & \multirow[b]{2}{*}{$\begin{array}{l}\text { Heated Humidifier, } \\
\text { median (IQR) }\end{array}$} & \multirow[b]{2}{*}{$\begin{array}{l}\text { Active HME, } \\
\text { median (IQR) }\end{array}$} & \multirow[b]{2}{*}{$\begin{array}{l}\text { HME, median } \\
\text { (IQR) }\end{array}$} & \multicolumn{4}{|c|}{$P$ Values } \\
\hline & & & & Overall* & $\begin{array}{c}\text { Heated } \\
\text { Humidifier vs } \\
\text { Active HME } \dagger\end{array}$ & $\begin{array}{c}\text { Heated } \\
\text { Humidifier } \\
\text { vs HME } \ddagger\end{array}$ & $\begin{array}{l}\text { Active } \\
\text { HME vs } \\
\text { HME§ }\end{array}$ \\
\hline $\mathrm{V}_{\mathrm{T}}, \mathrm{mL}$ & $341(282-435)$ & $322(271-434)$ & $322(300-398.50)$ & .80 & .55 & .36 & .97 \\
\hline$\dot{\mathrm{V}}_{\mathrm{E}}, \mathrm{L} / \mathrm{min}$ & $8.09(7.50-9.15)$ & $9.20(7.30-10.15)$ & $8.90(6.70-10.47)$ & .63 & .21 & .52 & .39 \\
\hline $\mathrm{PTP}_{\mathrm{di} / \text { breath }}, \mathrm{cm} \mathrm{H}_{2} \mathrm{O} \times \mathrm{s}$ & $3.11(1.27-4.30)$ & $4.50(1.50-8.90)$ & $4(2.89-8.91)$ & .07 & $.02 \|$ & $.038 \|$ & .39 \\
\hline $\mathrm{PTP}_{\mathrm{di} / \min }, \mathrm{cm} \mathrm{H}_{2} \mathrm{O} \times \mathrm{s} / \mathrm{min}$ & $80.86(25.46-110.55)$ & $117.10(34.58-298.60)$ & $107.50(71.47-238.80)$ & .09 & $.01 \Phi$ & .064 & .45 \\
\hline $\mathrm{f}$, breaths/min & $23.80(21.50-27.95)$ & $27.30(24.20-29.75)$ & $26.30(21.70-28.55)$ & .53 & .15 & .32 & .36 \\
\hline $\mathrm{PEEP}_{\mathrm{i}, \mathrm{dyn}}, \mathrm{cm} \mathrm{H}_{2} \mathrm{O}$ & $0.90(0.50-2.35)$ & $1.60(0.86-3.05)$ & $1.90(0.96-2.75)$ & .15 & .061 & .13 & .85 \\
\hline $\mathrm{T}_{\mathrm{I}} / \mathrm{T}_{\text {tot }}$ & $0.40(0.34-0.46)$ & $0.41(0.37-0.49)$ & $0.41(0.36-0.45)$ & .13 & $.045 \|$ & .41 & .40 \\
\hline $\mathrm{Cl}_{\mathrm{dyn}}, \mathrm{L} / \mathrm{cm} \mathrm{H}_{2} \mathrm{O}$ & $0.03(0.02-0.05)$ & $0.03(0.02-0.04)$ & $0.03(0.02-0.04)$ & .16 & .43 & $.030 \|$ & .33 \\
\hline $\mathrm{RL}, \mathrm{cm} \mathrm{H}_{2} \mathrm{O} / \mathrm{L} \times \mathrm{s}$ & $16.70(13.60-21.65)$ & $17.80(14.60-24.85)$ & $16.39(15.68-28.95)$ & .38 & .41 & .13 & .26 \\
\hline $\mathrm{pH}$ & $7.45(7.40-7.51)$ & $7.41(7.36-7.49)$ & $7.42(7.37-7.47)$ & $.006 \mathbb{I}$ & $.030 \|$ & $.01 \Phi$ & .71 \\
\hline $\mathrm{P}_{\mathrm{aCO}_{2}}, \mathrm{~mm} \mathrm{Hg}$ & $39.60(37.50-49.95)$ & $48.50(40.65-53.70)$ & $46.80(36.10-53.50)$ & .15 & $.02 \|$ & .16 & .29 \\
\hline $\mathrm{P}_{\mathrm{aO}_{2}}, \mathrm{~mm} \mathrm{Hg}$ & $73.50(65.25-83.70)$ & $70(62.90-80.20)$ & $69.80(63.75-82.20)$ & .45 & .33 & .17 & .30 \\
\hline Dyspnea scale & $4(3-5)$ & $3(2-4)$ & $3(1-4)$ & $.007 \Phi$ & $.009 \mathrm{I}$ & $.02 \|$ & $>.99$ \\
\hline $\begin{array}{l}\text { * } P \text { value denotes statistically signific } \\
\dagger P \text { value denotes statistically significe } \\
¥ P \text { value denotes statistically significe } \\
\S P \text { value denotes statistically significe } \\
\| P \text { value }<.05 \text {. } \\
\mathbb{I I} P \text { value }<.017 \text { (Bonferroni-adjusted } \\
\mathrm{HME}=\text { heat-and-moisture exchanger } \\
\mathrm{IQR}=\text { interquartile range } \\
\mathrm{V}_{\mathrm{T}}=\text { tidal volume } \\
\dot{\mathrm{V}}_{\mathrm{E}}=\text { minute ventilation } \\
\mathrm{PTP}_{\mathrm{di} / \text { breath }}=\text { pressure-time product pe } \\
\mathrm{PTP}_{\mathrm{di} / m i n}=\text { transdiaphragmatic pressu } \\
\mathrm{f}=\text { breathing frequency } \\
\mathrm{PEEP}_{\mathrm{i}, \mathrm{dyn}}=\text { dynamic intrinsic PEEP } \\
\mathrm{T}_{\mathrm{i}}=\text { inspiratory time } \\
\mathrm{T}_{\mathrm{tot}}=\text { total respiratory time } \\
\mathrm{Cl} \mathrm{l}_{\mathrm{dyn}}=\text { dynamic lung compliance } \\
\mathrm{RL}=\text { total lung resistance }\end{array}$ & $\begin{array}{l}\text { cant differences among Heated } \\
\text { ant differences between Heated } \\
\text { ant differences between Heated } \\
\text { ant differences between Active } \\
P \text { value for } 3 \text { between-device } \\
\text { I }\end{array}$ & $\begin{array}{l}\text { Humidifier, Active HME, and H } \\
\text { Humidifier and Active HME de } \\
\text { Humidifier and HME devices fo } \\
\text { HME and HME devices for eacl } \\
\text { comparisons). }\end{array}$ & $\begin{array}{l}\text { ME devices for each variable. } \\
\text { vices for each variable. } \\
\text { r each variable. } \\
\text { variable. }\end{array}$ & & & & \\
\hline
\end{tabular}

\section{Discussion}

To our knowledge, this was the first study to compare the physiologic effects of the active HME with such commonly used devices as HMEs and heated humidifiers in stable subjects who were tracheostomized and ventilatordependent. The main findings of our study were that the subjects' inspiratory effort and $\mathrm{P}_{\mathrm{aCO}}$ levels were significantly greater, and $\mathrm{pH}$ was significantly lower with the active HME compared with the heated humidifier. Moreover, subject tolerance and dyspnea were significantly worse with the active HME compared with the heated humidifier.

Results of previous in vitro studies indicated that both the HME and the active HME may interfere with pressuresupport ventilation due to the dead space that they add to the system. ${ }^{12,14-16,21}$ As a matter of fact, both devices are placed between the Y-piece (or the non-rebreathing system in the case of a single-limb circuit, such as in our study) and the patient; their internal volume, depending on

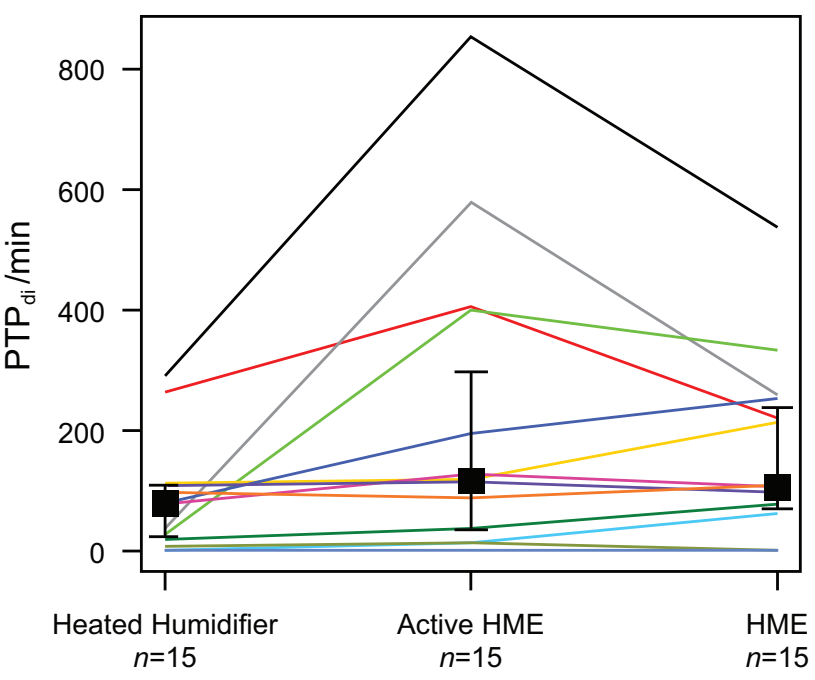

Fig. 2. Individual (pressure-time product of the diaphragm per minute $\left(\mathrm{PTP}_{\mathrm{di} / \mathrm{min}}\right)$ values during each trial. Each line represents data from a single record; black squares describe the median value of the variable's distribution by device, whereas whiskers delimit the interquartile range (25th-75th percentiles). 


\section{Short-Term Physiologic Effects of Active HMEs}

the manufacturer, can vary between 30 and $100 \mathrm{~mL},{ }^{6,12}$ potentially doubling or tripling the physiologic dead space. The internal volumes of the active HME and the HME according to the summary of product characteristics were 59 and $35 \mathrm{~mL}$, respectively.

Furthermore, it was shown in vitro that both the HME and the active HME can cause an increase in flow resistance, mainly due to the presence of the internal membrane. ${ }^{12}$ The active HME has also been shown to induce a greater increase in flow resistance compared with the HME; this has been ascribed to the accumulation of water within the device, as indicated by the weight increase. ${ }^{12}$ For 4 of 15 subjects, the trial had to be interrupted prematurely due to unbearable dyspnea and severe desaturation, and 3 of them developed respiratory acidosis.

It was also reported that, during both noninvasive and endotracheal mechanical ventilation, $6,7,9-11,22$ when compared with heated humidifiers, HMEs might be responsible for an increase in the patient's inspiratory effort and a reduction in alveolar ventilation with an increase in $\mathrm{P}_{\mathrm{aCO}_{2}}$ due to the huge resistive load and addition of dead space. As shown in Figure 2, in some subjects, the work of breathing did not change, whereas, in other subjects, the active HME apparently increased the pressure-time product of the diaphragm per minute. The other data of our subjects did not enable us to speculate about these results.

Our findings were consistent with these previous studies, 6,7-11,22 and added further insights into the clinical impact of the active HME device. As a matter of fact, we showed that, in stable subjects who were tracheostomized, the active HME, similar to the HME, induces an increase in patient inspiratory effort and impairs respiratory patterns, with a significant increase in $\mathrm{P}_{\mathrm{aCO}}$ compared with the heated humidifier. The active HME and the HME share a similar device structure and the same position along the ventilator circuit in such a way to increase the dead space and flow resistance. ${ }^{6,7}$ Moreover the $T_{I} / T_{\text {tot }}$ was significantly reduced during use of the active HME compared with the heated humidifier. These data, associated with a nonsignificant increase in dynamic intrinsic PEEP, further supported the hypothesis that the active HME may represent an even greater resistive load than the HME, due to the accumulation of a greater amount of water. In subjects with tracheostomy who are spontaneously breathing, a heated-and-humidified high-flow system was reported to achieve higher absolute humidity than did an HME. ${ }^{23}$

The active HME is increasingly being prescribed for long-term home mechanical ventilation as an alternative to heated humidifiers because it is lighter ( $42 \mathrm{~g}$ for the active HME vs $1.7 \mathrm{~kg}$ for the heated humidifier) and not cumbersome (the active HME consists of a mount catheter and a breathing filter connected to a booster vs several more components for the heated humidifier) and so it is able to facilitate the patient's movements. In addition to its opti- mum humidifying properties, which are particularly indicated for long-term invasive ventilation and similar to those of an active humidification system, as described elsewhere, ${ }^{12,13}$ the active HME was found to share similarities and handling features with the HME. ${ }^{12,13}$ However, practicality and humidifying properties are not the only 2 elements to consider when choosing such a device for longterm invasive ventilation. In fact, in this setting, patient tolerance and the impact on respiratory effort may significantly influence the efficacy of ventilation, as demonstrated by our findings.

In our study, the heated humidifier was shown to be superior to the other 2 devices in terms of physiologic effects and patient tolerance. Therefore, in our opinion, the heated humidifier should remain the device of choice. However, the active HME or the HME could also be considered, especially if preferred by patients and caregivers, but this may require a change of ventilatory setting to overcome the added dead space and resistive load that some patients who are ventilator-dependent are unable to tolerate.

Our study had some limitations. The sample-size calculation was performed on the basis of existing in vivo studies that compared heated humidifiers and HMEs devices. ${ }^{6,7}$ However, we could not exclude a beta effect in the lack of significant differences. The study enrolled a heterogeneous population of subjects with obstructive pulmonary diseases as well as restrictive and neuromuscular diseases. We used an arbitrary dyspnea scale that we routinely use in our patients' management, not a validated one. However, we are confident that this scale was appropriate for the purpose of the study. The Italian National Health Service, the third-party payer of health service, is organized on a regional basis, and we had no clear data on the current medical practice with this device or how the costs of, and associated with, the 3 devices differ over the country.

\section{Conclusions}

Our study indicated that, in stable subjects who were tracheostomized and ventilator-dependent, the use of the active HME or HME greatly increases patient inspiratory effort and significantly worsens $\mathrm{P}_{\mathrm{aCO}_{2}}$ and $\mathrm{pH}$ compared with the heated humidifier. Humidification devices, which are usually considered to be a minor technical detail and easily interchangeable, can have an important impact on physiologic parameters. In particular, this may be especially relevant for subjects who are invasively ventilated at home, where detection and treatment of clinical and physiologic worsening may be delayed and could lead to more severe consequences. This study was performed in subjects who were tracheostomized and ventilator-dependent; therefore, our findings were limited to these patients and could may not be applicable to other categories of patients. 


\section{Short-Term Physiologic Effects of Active HMEs}

\section{REFERENCES}

1. Branson RD. Secretion management in the mechanically ventilated patient. Respir Care 2007;52(10):1328-1342; discussion 1342-1247.

2. Peterson BD. Heated humidifiers. Structure and function. Respir Care Clin N Am 1998;4(2):243-259.

3. Wilkes AR. Heat and moisture exchangers. Structure and function. Respir Care Clin N Am 1998;4(2):261-279.

4. Diaz RB, Barbosa DA, Bettencourt AR, Vianna LAC, Gir E, Guimaraes T. Avaliacao do uso de filtros umidificadores higroscopicos para prevencao de pneumonia hospitalar (Evalution the use of hygroscopic humidifier filters to prevent nosocomial pneumonia) Acta Paulista de Enfermagem 2002;15(4):32-44.

5. Dreyfuss D, Djedaïni K, Gros I, Mier L, Le Bourdellés G, Cohen Y, et al. Mechanical ventilation with heated humidifiers or heat and moisture exchangers: effects on patient colonization and incidence of nosocomial pneumonia. Am J Respir Crit Care Med 1995;151(4): 986-992.

6. Lellouche F, Maggiore SM, Deye N, Taillé S, Pigeot J, Harf A, Brochard L. Effect of the humidification device on the work of breathing during noninvasive ventilation. Intensive Care Med 2002; 28(11):1582-1589.

7. Jaber S, Chanques G, Matecki S, Ramonatxo M, Souche B, Perrigault PF, Eledjam JJ. Comparison of the effects of heat and moisture exchangers and heated humidifiers on ventilation and gas exchange during non-invasive ventilation. Intensive Care Med 2002;28(11): 1590-1594.

8. Lellouche F, Pignataro C, Maggiore SM, Girou E, Deye N, Taillé S, et al. Short-term effects of humidification devices on respiratory pattern and arterial blood gases during noninvasive ventilation. Respir Care 2012;57(11):1879-1886.

9. Pelosi P, Solca M, Ravagnan I, Tubiolo D, Ferrario L, Gattinoni L. Effects of heat and moisture exchangers on minute ventilation, ventilatory drive and work of breathing during pressure support ventilation in acute respiratory failure. Crit Care Med 1996;24(7):11841188.

10. Iotti GA, Olivei MC, Palo A, Galbusera C, Veronesi R, Comelli A, et al. Unfavorable mechanical effects of heat and moisture exchangers in ventilated patients. Intensive Care Med 1997;23(4):399-405.

11. Le Bourdellès G, Mier L, Fiquet B, Djedaïni K, Saumon G, Coste F, Dreyfuss D. Comparison of the effects of heat and moisture exchangers and heated humidifiers on ventilation and gas exchange during weaning trials from mechanical ventilation. Chest 1996;110(5):12941298.

12. Pelosi P, Severgnini P, Selmo G, Corradini M, Chiaranda M, Novario $\mathrm{R}$, Park GR. In vitro evaluation of an active heat-and-moisture exchanger: the hygrovent gold. Respir Care 2010;55(4):460-466.

13. Gonzalez I, Jimenez P, Valdivia J, Esquinas A. Effectiveness of humidification with heat and moisture exchanger-booster in tracheostomized patients. Indian J Crit Care Med 2017;21(8):528-530.

14. MacIntyre NR, Epstein SK, Carson S, Scheinhorn D, Christopher K, Muldoon S. Management of patients requiring prolonged mechanical ventilation-report of a NAMDRC consensus conference. Chest 2005;128(6):3937-3954.

15. Baydur A, Behrakis PK, Zin WA, Jaeger M, Milic-Emili J. A simple method for assessing the validity of the esophageal balloon technique. Am Rev Respir Dis 1982;126(5):788-791.

16. Appendini L, Purro A, Patessio A, Zanaboni S, Carone M, Spada E, et al. Partitioning of inspiratory muscle workload and pressure assistance in ventilator-dependent COPD patients. Am J Respir Crit Care Med 1996;154(5):1301-1309.

17. Sassoon CS, Light RW, Lodia R, Sieck GC, Mahutte CK. Pressuretime product during continuous positive airway pressure, pressure support ventilation, and T-piece during weaning from mechanical ventilation. Am Rev Respir Dis 1991;143(3):469-475.

18. Faul F, Erdfelder E, Lang AG, Buchner A. G*Power 3: A flexible statistical power analysis program for the social, behavioral, and biomedical sciences. Behav Res Methods 2007;39(2):175-191.

19. Faul F, Erdfelder E, Buchner A, Lang AG. Statistical power analyses using $G^{*}$ Power 3.1: Tests for correlation and regression analyses. Behav Res Methods 2009;41(4):1149-1160.

20. Altman DG, Bland JM. How to randomise. BMJ 1999;319(7211): 703-704.

21. Chiaranda M, Verona L, Pinamonti O, Dominioni L, Minoja G, Conti G. Use of heat and moisture exchanging (HME) filters in mechanically ventilated ICU patients: influence on airway flow-resistance. Intensive Care Med 1993;19(8):462-466.

22. Campbell RS, Davis K Jr, Johannigman JA, Branson RD. The effects of passive humidifier dead space on respiratory variables in paralyzed and spontaneously breathing patients. Respir Care 2000;45(3): 306-312.

23. Nakanishi N, Oto J, Itagaki T, Nakataki E, Onodera M, Nishimura M. Humidification performance of passive and active humidification devices within a spontaneously breathing tracheostomized cohort. Respir Care 2019;64(2):130-135.

This article is approved for Continuing Respiratory Care Education credit. For information and to obtain your CRCE

(free to AARC members) visit

www.rcjournal.com

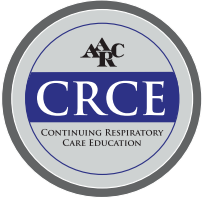

